\title{
Perbedaan Pengetahuan Siswa Sebelum dan Sesudah Pemberian Pendidikan Kesehatan Tentang Perilaku Hidup Bersih Sehat (PHBS) di SMK Negeri 6 Sukoharjo
}

\section{Differences in Student Knowledge Before and After Providing Health Education About Healthy Clean Living Behavior (PHBS) at SMK Negeri 6 Sukoharjo}

\author{
Euis Win Farida ${ }^{1}$, Suryono $^{2}$, Nine Elissa Maharani ${ }^{3}$ \\ Program Studi Kesehatan Masyarakat \\ Universitas Veteran Bangun Nusantara \\ Email : elissapanjimomo@gmail.com
}

\begin{abstract}
As a result of students' knowledge about healthy hygiene behaviors is low, so students cannot apply healthy hygiene behaviors correctly then students do not apply them in daily life, so that it will affect the low health status of the body. This study aims to determine the differences in student knowledge before and after the provision of health education about Healthy Clean Living Behavior (PHBS) at SMK Negeri 6 Sukoharjo.

This research is a Quasi Experiment Design with a "One group pretest-posttest design" design. The population is all students of class XI at SMK Negeri 6 Sukoharjo in the 2016/2017 school year with a total of 107 students. Sampling technique with a purposive sampling of 102 students. The independent variable is health education about PHBS. The dependent variable is students' knowledge about PHBS. The instrument used was a questionnaire. Analysis by "Paired t Test" ( $\alpha$ 5\%).

The results of this study the knowledge of students before the provision of health education an average of 11.92 with the lowest value of 4 and the highest 17 . Student knowledge after the provision of health education an average of 14.32 with the lowest value of 9 and the highest 19. In the paired t-test or paired t-test, the mean difference between the pre-test and post-test was 2,402 and the value of $p=0,000$ ( $p$ value $<0.05$ ). Conclusion there are differences in students' knowledge before and after the provision of health education about Healthy Clean Living Behavior (PHBS) at SMK Negeri 6 Sukoharjo.

From this research it is suggested that schools be encouraged to take part in giving attention to students in terms of Healthy Clean Living Behavior (PHBS) by including PHBS points in the material provided to students.
\end{abstract}

Keywords: Knowledge, Health Education, PHBS

References 36 (2003-2017)

\begin{abstract}
ABSTRAK
Akibat pengetahuan siswa tentang perilaku hidup bersih sehat rendah, sehingga siswa tidak bisa menerapkan perilaku hidup bersih sehat dengan benar maka siswa tidak menerapkannya dalam kehidupan sehari-hari, sehingga akan berpengaruh pada derajat kesehatan tubuh yang rendah. Penelitian ini bertujuan untuk mengetahui adanya perbedaan pengetahuan siswa sebelum dan sesudah pemberian pendidikan kesehatan tentang Perilaku Hidup Bersih Sehat (PHBS) di SMK Negeri 6 Sukoharjo.

Penelitian ini adalah Quasi Experiment Design dengan rancangan "One group pretestposttest design". Populasi adalah seluruh siswa kelas XI di SMK Negeri 6 Sukoharjo tahun ajaran 2016/2017 dengan jumlah 107 siswa. Tehnik sampling dengan purposive sampling
\end{abstract}


sebanyak 102 siswa. Variabel bebas adalah pendidikan kesehatan tentang PHBS.Variabel terikat adalah pengetahuan siswa tentang PHBS. Instrumen yang digunakan adalah kuesioner. Analisa dengan "Paired t Test" (Uji T berpasangan) dengan $\alpha$ 5\%.

Hasil dari penelitian ini pengetahuan siswa sebelum pemberian pendidikan kesehatan rata-rata 11,92 dengan nilai terendah 4 dan tertinggi 17 . Pengetahuan siswa sesudah pemberian pendidikan kesehatan rata-rata 14,32 dengan nilai terendah 9 dan tertinggi 19. Pada uji t-test berpasangan atau paired $t$-test terlihat perbedaan nilai mean antara pre-test dan post-test sebesar 2.402 dan nilai $p=0,000$ (nilai $p<0,05$ ). Kesimpulan ada perbedaan pengetahuan siswa sebelum dan sesudah pemberian pendidikan kesehatan tentang Perilaku Hidup Bersih Sehat (PHBS) di SMK Negeri 6 Sukoharjo.

Dari penelitian ini disarankan sekolah terdorong untuk turut memberikan perhatian terhadap siswa dalam hal Perilaku Hidup Bersih Sehat (PHBS) dengan memasukkan point PHBS dalam materi yang diberikan pada siswa.

Kata Kunci : Pengetahuan, Pendidikan Kesehatan, PHBS

Daftar Pustaka 36 (2003-2017)

\section{PENDAHULUAN}

Salah satu bentuk program promosi kesehatan yang telah diterapkan oleh pemerintah terkait dengan masalah kesehatan adalah Perilaku hidup bersih dan sehat (PHBS). Perilaku hidup bersih dan sehat adalah upaya yang dilakukan oleh Departemen Kesehatan untuk membudayakan perilaku hidup bersih dan sehat di semua bidang kehidupan agar terwujud pribadi dan lingkungan yang sehat demi mencapai derajat kesehatan optimal dan kesejahteraan bangsa sesuai yang diamatkan dalam Pembukaan Undang-Undang Dasar 1945 (Farida, 2009).

Perilaku hidup bersih dan sehat di sekolah adalah sekumpulan perilaku yang dipraktikkan oleh peserta didik, guru dan masyarakat lingkungan sekolah atas dasar kesadaran sebagai hasil pembelajaran, sehingga secara mandiri mampu mencegah penyakit, meningkatkan kesehatan, serta berperan aktif dalam mewujudkan lingkungan sekolah sehat (Sari, 2013). Sebagai generasi penerus, usia sekolah dengan jumlah 30\% dari jumlah penduduk Indonesia memiliki potensi untuk menjadi agen perubahan dalam hal mempromosikan PHBS (Sari, 2013).

Program pembinaan perilaku hidup bersih dan sehat yang sudah dilakukan pemerintah Dinas Kesehatan Provinsi Jawa Tengah yaitu mengadakan survei cepat tentang perilaku siswa menerapkan kebiasaan PHBS di sekolah untuk mengetahui tentang kebiasaan hidup sehat bagi anak-anak di sekolah mulai dari tingkat SD, SMP dan SMU. Adapun indikator yang digunakan adalah delapan indikator yaitu kebiasaan mencuci tangan, menggunakan jamban sekolah, kebiasaan jajan sehat di kantin sekolah, mengikuti kegiatan olahraga dan aktifitas fisik, pemberantasan jentik nyamuk, kebiasaan merokok, menimbang berat badan dan tinggi badan serta membuang sampah pada tempatnya (Dinas Kesehatan Jawa Tengah, 2011).

Perilaku akan pentingnya kesehatan lingkungan di sekolah menjadi dasar terciptanya kesehatan lingkungan secara keseluruhan. Kondisi sehat dapat dicapai dengan mengubah perilaku dari tidak sehat dan menciptakan lingkungan sehat di sekolah. Perubahan ini dapat dilakukan melalui promosi kesehatan (Fitriani, 2011).

Program promosi kesehatan yang dilakukan harus dengan metode yang tepat sehingga nantinya siswa-siswi memperoleh informasi yang tepat tentang perilaku hidup bersih dan sehat yang benar. Pengetahuan merupakan domain yang sangat penting bagi terbentuknya 
perilaku seseorang. Pengetahuan akan merangsang terjadinya perubahan sikap dan bahkan tindakan seorang individu (Efendi \& Makhfudli, 2008).

Sehubungan dengan hal tersebut, tidak hanya peran sekolah perilaku yang kurang sehat ini dapat pula menimbulkan persoalan yang lebih serius seperti ancaman penyakit menular. Sekolah merupakan sumber penularan penyakit infeksi di sekolah antara lain: infeksi tangan dan mulut, infeksi mata, demam berdarah, cacar air, campak, dan gondong. Jika siswa sekolah tidak memahami perilaku hidup bersih dan sehat bukan tidak mungkin dapat menekan tingginya angka penyakit tersebut. Maka pengetahuan yang ada di sekolah perlu ditingkatkan dengan cara memberikan kesempatan untuk mempraktekkan seminggu sekali ataupun dengan cara pendalaman materi tentang perilaku hidup bersih dan sehat (Notoatmodjo, 2010a).

Akibat pengetahuan siswa tentang perilaku hidup sehat rendah, maka siswa tidak bisa menerapkan perilaku hidup sehat dengan benar atau bahkan tidak menerapkannya dalam kehidupan sehari-hari, sehingga akan berpengaruh pada derajat kesehatan tubuh yang rendah. Perlunya penanganan dan solusi untuk itu dengan meningkatkan pengetahuannya, memahami, dan mempraktekannya di lingkungan sekolah dan untuk dirinya sendiri (Notoatmodjo a, 2010).

Pengetahuan siswa tentang perilaku hidup sehat sangatlah penting, karena pengetahuan siswa yang tinggi terhadap perilaku hidup sehat akan menjadi pendorong timbulnya usaha sadar siswa untuk menjaga dan meningkatkan kesehatannya melalui perilaku hidup sehat, menurut Notoatmodjo (2010) Pengetahuan merupakan dampak dari informasi yang ditangkap oleh indera manusia dan merupakan domain yang sangat penting dalam membentuk tindakan seseorang.

Hasil studi pendahuluan yang dilakukan tanggal 3 Maret 2017 di SMK Negeri 6 Sukoharjo diketahui bahwa SMK Negeri 6 Sukoharjo kelas XI memiliki 351 siswa yang terbagi menjadi 10 kelas yaitu kelas Akuntansi 3 kelas 107 siswa, Multimedia 4 kelas 137 siswa dan teknik Sepeda Motor 3 kelas 107 siswa. Diketahui pula bahwa SMK Negeri 6 Sukoharjo terletak di dekat tempat pembuangan sampah yang dapat menimbulkan lingkungan yang tidak sehat. Melalui wawancara dengan 10 siswa di SMK Negeri 6 Sukoharjo diketahui $60 \%$ siswa SMK mempunyai pengetahuan yang kurang mengenai PHBS tatanan sekolah serta didapatkan informasi bahwa SMK Negeri 6 Sukoharjo merupakan Sekolah Menengah Kejuruan yang sudah menerapkan tentang hidup bersih sehat di sekolah dengan memberikan materi tentang kesehatan lingkungan sekolah namun pada kenyataannya tidak $60 \%$ siswa kelas XI Di SMK Negeri 6 Sukoharjo kurang bersih dan rapi dalam berpakaian dan bersepatu, ada yang membuang sampah tidak pada tempatnya, siswa tidak mencuci tangan setelah berolahraga dan sebelum makan, siswa memiliki gigi berlubang, kantin yang kurang bersih, siswa memiliki kuku yang panjang dan tidak bersih. Diketahui dari hasil penjaringan yang dilakukan oleh tim UKS Puskesmas Gatak didapatkan data bahwa siswa kelas XI teknik sepeda motor terdapat 30\% siswa yang merokok hal ini sangat bertentangan dengan perilaku hidup bersih sehat yang diterapkan oleh SMK Negeri 6 Sukoharjo.

Berdasarkan fenomena pada siswa kelas XI Di SMK Negeri 6 Sukoharjo tentang masalah yang berhubungan dengan Perilaku Hidup Bersih Sehat (PHBS) yang sudah diterapkan akan tetapi masih ada siswa yang kurang memperhatikan kesehatan lingkungan sekolah, terutama pada kebersihan diri sendiri, permasalahan tersebut membuat peneliti tertarik untuk mengetahui bagaimana perbedaan pengetahuan siswa sebelum dan sesudah pemberian pendidikan kesehatan tentang Perilaku Hidup Bersih Sehat (PHBS) di SMK Negeri 6 Sukoharjo. Rumusan masalah dalam penelitian ini adalah "Adakah perbedaan pengetahuan siswa sebelum dan sesudah pemberian pendidikan kesehatan tentang Perilaku Hidup Bersih Sehat (PHBS) di SMK Negeri 6 Sukoharjo?" Untuk mengetahui adanya 
perbedaan pengetahuan siswa sebelum dan sesudah pemberian pendidikan kesehatan tentang Perilaku Hidup Bersih Sehat (PHBS) di SMK Negeri 6 Sukoharjo.

\section{METODE}

Penelitian ini merupakan jenis penelitian eksperimen yang digunakan adalah quasi experiment designs dengan one group pretest-posttest design. Lokasi penelitian di SMK Negeri 6 Sukoharjo dan waktu pengumpulan data pada 27 September 2017.

Teknik sampling digunakan dalam penelitian ini adalah (purposive sampling) adalah pengambilan sampel dilakukan sedemikian rupa sehingga kewakilannya ditentukan oleh peneliti berdasarkan pertimbangan peneliti (Budiarto, 2014). Diketahui dari hasil penjaringan yang dilakukan oleh tim UKS Puskesmas Gatak didapatkan data bahwa siswa kelas XI teknik sepeda motor terdapat 30\% siswa yang merokok hal ini sangat bertentangan dengan perilaku hidup bersih sehat yang diterapkan oleh SMK Negeri 6 Sukoharjo. Dalam penelitian ini sampel adalah seluruh siswa kelas XI Teknik Sepeda Motor berjumlah 102 siswa hal ini dikarenakan terdapat 5 siswa yang tidak masuk.

\section{HASIL DAN PEMBAHASAN}

\section{Analisa Univariat}

a. Hasil nilai pre-test pengetahuan siswa sebelum pemberian pendidikan kesehatan tentang Perilaku Hidup Bersih Sehat (PHBS).

Tabel 4 Nilai pre-test pengetahuan siswa tentang PHBS di SMK Negeri 6 Sukoharjo

\begin{tabular}{cccc}
\hline No & Nilai & Jumlah Responden & Prosentase \\
\hline 1 & 4 & 1 & 0,98 \\
2 & 7 & 6 & 5,88 \\
3 & 8 & 9 & 8,82 \\
4 & 9 & 6 & 5,88 \\
5 & 10 & 9 & 8,82 \\
6 & 11 & 8 & 7,84 \\
7 & 12 & 19 & 18,63 \\
8 & 13 & 10 & 9,80 \\
9 & 14 & 14 & 13,73 \\
10 & 15 & 10 & 9,80 \\
11 & 16 & 8 & 7,84 \\
12 & 17 & 2 & 1,96 \\
\hline \multicolumn{5}{r}{} & jumlah & 102 & 100 \\
\hline
\end{tabular}

Sumber : data primer tahun 2017

Tabel 5 Nilai pre-test pengetahuan siswa tentang PHBS di SMK Negeri 6 Sukoharjo

\begin{tabular}{clcc}
\hline No & Kategori & Hasil & Std Deviasi \\
\hline 1 & Mean & 11,92 & 2,796 \\
2 & Median & 12,00 & \\
3 & Modus & 12 & \\
\hline
\end{tabular}

Sumber : data primer tahun 2017 
Tabel 5 menunjukkan bahwa nilai pre-test pengetahuan siswa tentang PHBS rata-rata 11,92 dengan nilai tengahan 12,00 , nilai yang paling banyak muncul adalah 12, nilai terendah 4 dan nilai tertinggi 17.

a. Hasil nilai post-test pengetahuan siswa setelah pemberian pendidikan kesehatan tentang Perilaku Hidup Bersih Sehat (PHBS).

Tabel 6 Nilai post-test pengetahuan siswa tentang PHBS di SMK

Negeri 6 Sukoharjo

\begin{tabular}{|c|c|c|c|}
\hline No & Nilai & Jumlah Responden & Prosentase \\
\hline 1 & 9 & 4 & 3,92 \\
\hline 2 & 10 & 8 & 7,84 \\
\hline 3 & 11 & 5 & 4,90 \\
\hline 4 & 12 & 6 & 5,88 \\
\hline 5 & 13 & 17 & 16,67 \\
\hline 6 & 14 & 11 & 10,78 \\
\hline 7 & 15 & 14 & 13,73 \\
\hline 8 & 16 & 14 & 13,73 \\
\hline 9 & 17 & 12 & 11,76 \\
\hline 10 & 18 & 4 & 3,92 \\
\hline \multirow[t]{2}{*}{11} & 19 & 7 & 6,86 \\
\hline & Jumlah & 102 & 100 \\
\hline
\end{tabular}

Sumber : data primer tahun 2017

Tabel 7 nilai post-test pengetahuan siswa tentang PHBS di SMK Negeri 6 Sukoharjo

\begin{tabular}{clcc}
\hline No & Kategori & Hasil & Std Deviasi \\
\hline 1 & Mean & 14,32 & 2,671 \\
2 & Median & 14,50 & \\
3 & Modus & 13 & \\
\hline
\end{tabular}

Sumber : data primer tahun 2017

Tabel 7 menunjukkan bahwa nilai post-test pengetahuan siswa tentang PHBS rata-rata 14,32 dengan nilai tengahan 14,50, nilai yang paling banyak muncul adalah 13, nilai terendah 9 dan nilai tertinggi.

\section{Analisa Bivariat}

Perbedaan pengetahuan siswa sebelum dan sesudah pemberian pendidikan kesehatan tentang Perilaku Hidup Bersih Sehat (PHBS) di SMK Negeri 6 Sukoharjo. Analisa bivariat dalam penelitian ini dimaksudkan untuk mengetahui perbedaan pengetahuan siswa tentang Perilaku Hidup Bersih Sehat (PHBS) sebelum dan sesudah pemberian pendidikan kesehatan tentang Perilaku Hidup Bersih Sehat (PHBS) dengan cara mengetahui perbedaan nilai pada pre-test dan post-test dari kuesioner tentang Perilaku Hidup Bersih Sehat (PHBS).

Analisa Bivariat dalam penelitiannya ini menggunakan uji t-test berpasangan atau paired t-test. Sebelum dilakukan analisa bivariat terlebih dahulu dilakukan Uji normalitas data pada keseluruhan hasil data kuesioner dari pre-test dan post-test. Dari hasil uji normalitas data didapatkan bahwa pada data pre-test dan post-test pada nilai Kolmogorov-Smirnov $Z$ dengan hasil Zhitung pretest $(1,301)$ dan posttest $(1,010)$ yang kemudian dibandingkan dengan harga $\mathrm{Z}$ tabel $(1,96)$ dengan demikian $\mathrm{Z}$ hitung 
$<\mathrm{Z}$ tabel sehingga semua data berdistribusi normal sehingga analisis bivariat akan dilakukan uji t-test berpasangan atau paired t-test.

Tabel 8 Hasil uji t-test berpasangan atau paired t-test

\begin{tabular}{|c|c|c|c|c|}
\hline $\mathrm{Nc}$ & variabel & & Mean & Sig. \\
\hline 1 & pre-test & & 11,92 & 0,000 \\
\hline \multirow[t]{2}{*}{2} & post-test & & 14,32 & \\
\hline & Beda pre-test dan & post-test & 2.402 & \\
\hline
\end{tabular}

Sumber : data primer tahun 2017

Tabel 8 hasil uji t-test berpasangan atau paired t-test diketahui hasil pre-test sebelum penyuluhan skor rata-rata adalah 11,92 , sedangkan pada post-test skor ratarata 14,32. Dari perbedaan skor pre-test dan post-test tersebut artinya terjadi peningkatan pengetahuan siswa tentang PHBS. Pada uji t-test berpasangan atau paired t-test terlihat perbedaan nilai mean antara pre-test dan post-test sebesar 2.402 dan nilai $\mathrm{p}=0,000$ (nilai $\mathrm{p}<0,05$ ), maka $\mathrm{H} 0$ ditolak dan Ha diterima, artinya ada perbedaan pengetahuan siswa sebelum dan sesudah pemberian pendidikan kesehatan tentang Perilaku Hidup Bersih Sehat (PHBS) di SMK Negeri 6 Sukoharjo.

\section{KESIMPULAN}

Berdasarkan hasil penelitian dan pembahasan mengenai Perbedaan Pengetahuan Siswa Sebelum dan Sesudah Pemberian Pendidikan Kesehatan Tentang Perilaku Hidup Bersih Sehat (PHBS) dilaksanakan di SMK Negeri 6 Sukoharjo, maka dapat disimpulkan bahwa :

a. Pengetahuan siswa sebelum pemberian pendidikan kesehatan tentang Perilaku Hidup Bersih Sehat (PHBS) mendapatkan nilai rata-rata 11,92.

b. Pengetahuan siswa sesudah pemberian pendidikan kesehatan tentang Perilaku Hidup Bersih Sehat (PHBS) mendapatkan nilai rata-rata 14,32

c. Ada perbedaan pengetahuan siswa sebelum dan sesudah pemberian pendidikan kesehatan tentang Perilaku Hidup Bersih Sehat (PHBS) dengan nilai $p=0,000$.

\section{SARAN}

a. Diharapkan sekolah dapat memanfaatkan hasil penelitian ini untuk memberikan perhatian terhadap siswa dalam hal Perilaku Hidup Bersih Sehat (PHBS) dengan memasukkan point PHBS dalam materi yang diberikan pada siswa.

b. Diharapkan puskesmas dapat memanfaatkan hasil penelitian ini untuk menentukan tindak lanjut yang perlu dilakukan pada siswa sebagai sasaran pendidikan kesehatan dan pada sekolah sebagai pembuat kebijakan.

c. Diharapkan peneliti dapat menggunakan hasil penelitian ini untuk penelitian lebih lanjut dan menerapkan pada sosial masyarakat.

\section{DAFTAR PUSTAKA}

Arifiani. 2011. Perbedaan peningkatan pengetahuan tentang PHBS antara metode permainan monopoli dan ceramah. www. erepo.unud.ac.id. Diakses tanggal 13 Maret 2017

Arikunto S. 2010. Prosedur Penelitian Suatu Pendekatan Praktik. Jakarta : Rineka Cipta 
Azwar. 2008. Besar dan Metode Sampel Pada Penelitian Kesehatan, Depok : Jurusan Biostatistik dan Kependudukan FKM UI.

Budiarto E. 2014. Metodologi Penelitian Kedokteran. Jakarta : EGC.

Depkes RI. 2007.Rumah Tangga Sehat Dengan Perilaku Hidup Bersih dan Sehat. Jakarta : Kemenkes

Departemen Kesehatan RI. 2010. Pedoman Pelaksanaan PHBS Bagi Masyarakat Di Wilayah Kecamatan. Jakarta : Kemenkes

Diar. 2009. Ilmu Sosial Masyarakat Dipandang dari Segi Medis. http:www.forbetterhealth.wordpress.com. Diakses tanggal 13 Maret 2017.

Dinas Kesehatan Jawa Tengah. Laporan Survey BMS Jawa Tengah MHCR PKPU Pusat. Jawa Tengah. Pusat Data Kesehatan Depkes RI 1998, Metode Survey Cepat

DinKes Jabar. 2010. Buku Saku Pelaksanaan PHBS Bagi Sekolah. Jawa Barat : Dinas Kesehatan

Evayanti. 2012. Faktor - Faktor Yang Mempengaruhi Tingkat Perilaku Hidup Bersih dan Sehat (PHBS)

Farida. 2009. Perilaku Hidup Bersih dan Sehat (PHBS). Yogyakarta: Nuha Medika

Fitriani S. 2011. Promosi Kesehatan. Yogyakarta : Graha Ilmu.

Efendi \& Makhfudli. 2008. Pengetahuan dan Faktor-Faktor Yang Mempengaruhi PHBS, http:www.forbetterhealth.wordpress.com. Diakses tanggal 13 Maret 2017.

Hidayat A. 2008. Catatan Kuliah Konsep Kebidanan Plus Materi Bidan Delima. Yogyakarta : Mitra Cendikia.

Ismoyowati. 2008. Buku Saku Pelaksanaan PHBS Bagi Masyarakat Di Wilayah Kecamatan.Jakarta : Kemenkes

Kholid A. 2015. Promosi Kesehatan: Dengan pendekatan teori perilaku, media, dan aplikasinya. Rajawali Pers : Jakarta

Lubis. 2009. Faktor - Faktor Yang Mempengaruhi Tingkat Perilaku Hidup Bersih dan Sehat (PHBS)

Menkes RI. 2011. Sasaran PHBS di Tatanan Institusi Pendidikan. Jakarta : Kemenkes

Nana. 2005. Hubungan Pengetahuan Dan sikap Keluarga Terhadap Perilaku Hidup Bersih dan Sehat Wilayah Kerja Puskesmas Lubuk Alung tahun 2009. Laporan penelitian : UNAND.

Notoatmodjo S. 2003. Pendidikan dan Perilaku Kesehatan. Jakarta :Rineka Cipta 
Jurnal Ilmu Kesehatan Masyarakat Berkala (2019); (1) 1: 41-48

Nursalam. 2005. Konsep Dan Penerapan Metodologi Penelitian Ilmu Keperawatan :Pedoman Skripsi, Tesis Dan Instrumen Penelitian Keperawatan, Jakarta : Salemba Medika,.

Prasetyo. 2009. Evaluasi untuk Pendidikan Kesehatan. www.luriaingrassia. blogspot.com. Diakses tanggal 21 Maret 2017.

Promkes. 2016. Perilaku Hidup Bersih Sehat. Promosi Kesehatan Bagi Siswa. www. erepo.unud.ac.id. Diakses tanggal 13 Maret 2017.

Proverawati. 2012. Pendidikan Kesehatan Bagian Dari Promosi Kesehatan Yugyakarta. Penerbit Fitramaya

Riwidigdo H. 2010. Statistik Kesehatan. Jogjakarta : Mitra Cendikia.

Sari S. 2013. Hubungan Faktor predisposisi dengan Perilaku Personal Higine Anak Jalanan Bimbinghan Rumah Singgah YMS Bandung, Skripsi, Keperawatan Komunitas Fakultas Ilmu Keperawatan Universitas Padjadjaran, Bandung

Septalia. 2011. Pengaruh Pendidikan Kesehatan terhadap pengetahuan ibu hamil tentang PHBS tatanan Rumah Tangga. www. eprints.ung.ac.id. Diakses tanggal 21 Maret 2017.

Sugiyono. 2008. Statistik Untuk Penelitian. Bandung : CV. Alfabeta.

Sumiyati Asra. 2008. Ilmu Kesehatan Masyarakat. Jakarta : EGC

Syamsur Manda. 2016. Perilaku Hidup Bersih Sehat. www. luriaingrassia. blogspot.com. Diakses tanggal 21 Maret 2017.

Sya'roni RS. 2007. Penerapan PHBS di Sekolah. http://digilib.unimus.ac.id. Diakses tanggal 13 Maret 2017.

Taufiqurohman M A. 2008. Pengantar Metodologi Penelitian untuk Ilmu Kesehatan. Surakarta : UNS Pers

Walgito. 2003. Ilmu Kesehatan Masyarakat. http:www.forbetterhealth. wordpress.com. Diakses tanggal 24 Maret 2017.

Yanti. 2010. Faktor - Faktor Yang Mempengaruhi Tingkat Perilaku Hidup Bersih dan Sehat (PHBS) Tatanan Sekolah Kabupaten Sukoharjo 2010. 